\title{
PREFACE: ACADEMICIAN VLADIMIR PAVLOVICH SKRIPOV (1927-2006)
}

The present issue of the journal Interfacial Phenomena and Heat Transfer is devoted to Professor Vladimir Pavlovich Skripov; an academician of the Russian Academy of Sciences, and the founder of the Russian School of Thermal Physics. Skripov was born on June 16, 1927 in Leningrad. He became involved in research work during his student years at Moscow State University (MSU) under the guidance of Professor V.K. Semenchenko.

During 1951-1953, as a postgraduate student at MSU, he carried out a series of experiments in which the existence of maximum heat capacity at a critical point was first established for stratifiable solutions. Along with subsequent investigations of light scattering in the vicinity of a liquid-vapor critical point, this work made a noticeable contribution to the formation of present-day views of critical phenomena in liquids.

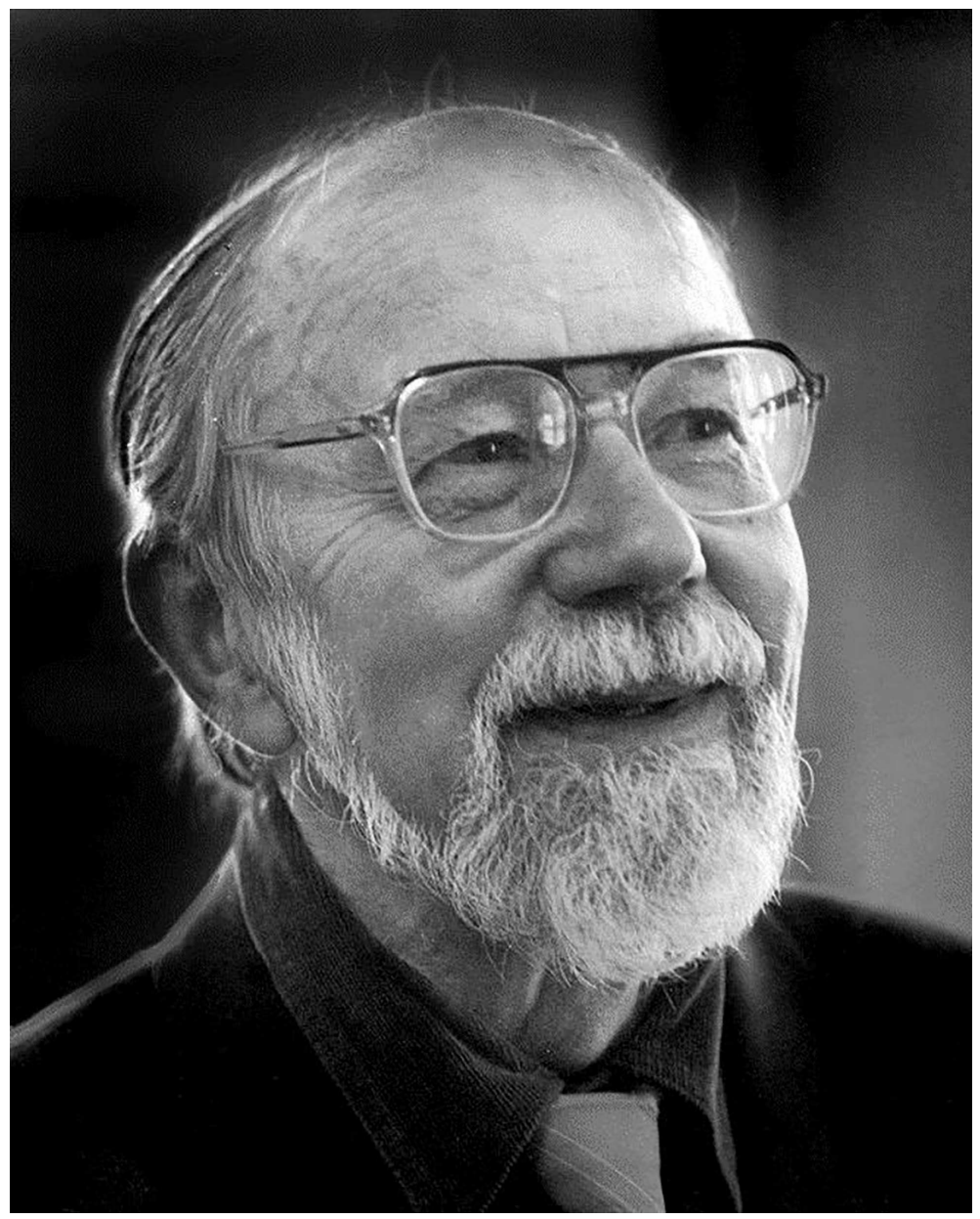

FIG. 1: Academician Vladimir Pavlovich Skripov (1927-2006) 
After defending his thesis for a degree in physical and mathematical sciences in 1953, V.P. Skripov moved to Sverdlovsk (now Ekaterinburg), where he began his teaching career at the Molecular Physics Department of the physico-technical faculty at Ural Polytechnical Institute (now Ural Federal University). His interest in the boiling of liquids led him to formulate the idea of a thermodynamic boiling crisis, and evidently led to his awareness of the work of Japanese researchers H. Wakeshima and K. Takata, who had observed high superheatings of pentane and hexane at atmospheric pressure. Later, V.P. Skripov said that it was precisely this publication that not only caused his emotional reaction, but also incited him to formulate a program of work in this direction.

In 1961, V.P. Skripov, together with student V.J. Kukushkin, repeated the experiments conducted by H. Wakeshima and K. Takata (1958), supplementing them with investigations of the attainable superheating of solutions. Then, with postgraduate student G.V. Ermakov, he modernized the apparatus used by the Japanese researchers, locating it in a high-pressure chamber, and began to measure the superheating temperature of hydrocarbon droplets at elevated pressures. These experiments gave rise to the idea of measuring the lifetime of a superheated liquid as a new means of studying nucleation kinetics. Another one of his postgraduate students, E.N. Sinitsyn, began to formulate this idea. This initiated the method that was subsequently called the method of mean lifetime determination. The experiments conducted led to surprising results, namely, the Poisson distribution of expectation times for boiling-up, and made it possible to register the initiating action of the natural radiation background on nucleation kinetics. At the same time, V.P. Skripov, together with P.A. Pavlov, formulated the notion of the shock regime of boiling-up a superheated liquid, which led to the development of a new method of investigating superheated liquids, i.e., the method of pulsed liquid superheating on thin platinum wires. The methods of lifetime measurement, emergent drops, and pulsed superheating allowed covering for the first time a range of nucleation rates from $10^{4}$ to $10^{26} \mathrm{~s}^{-1} / \mathrm{m}^{-3}$.

In 1965, V.P. Skripov organized a laboratory of thermal physics at the Ural Branch of the USSR Academy of Sciences (now the Ural Branch of the Russian Academy of Sciences). This was the beginning of his work at the USSR Academy of Sciences. He was transferred there in 1972 to the position of the director of the Department of Physico-Technical Problems of Energetics, and then became the head of the Institute of Thermal Physics of the Ural Branch of the Russian Academy of Sciences created on this basis (in 1988). In 1967, V.P. Skripov defended a thesis for a doctorate degree in physics and mathematics. The materials of this thesis formed the basis for the monograph "Metastable Liquids" published in 1972, which was subsequently translated into English (Skripov, 1974).

Along with the work on the study of nucleation kinetics, investigations of thermophysical properties of superheated liquids were conducted. V.P. Skripov formulated the notion of a spinodal as an envelope of isochores. Together with his pupils, he performed experiments on the measurement of specific volumes (G.V. Ermakov and V.G. Baidakov), ultrasonic velocity (V.G. Baidakov and G.V. Ermakov), isochoric heat capacity and ultrasound adsorption (V.G. Baidakov), and thermal conductivity and viscosity (N.V. Bulanov) of superheated liquids. A considerable part of the results obtained was included in the monograph "Thermodynamical Properties of Liquids in a Metastable State" written by V.P. Skripov in co-authorship with his pupils and published in Russian in 1980 and in English in 1988 (Skripov et al., 1988).

The work on the crystallization of supercooled liquids (G.V. Butorin and V.P. Koverda), which began in 1969, was subsequently reflected in the monograph by V.P. Skripov and V.P. Koverda on "Spontaneous Crystallization of Supercooled Liquids" (Skripov and Koverda, 1984).

After V.P. Skripov started working at the USSR Academy of Sciences, his work on phase metastability was considerably extended. A study was made of flows of boiling-up liquids, new procedures were developed for measuring thermodynamic properties of substances in stable and metastable states, and work began on the study of cryogenic liquids, superconductivity, electrolytes, etc.

V.P. Skripov developed the general concept of phase metastability. He introduced the notion of a well-determined metastable state, the hierarchy of characteristic times of existence of nonequilibrium structures, suggested a new approach to thermodynamic similarity in a liquid-crystal system based on the low-temperature asymptotics of the melting curve. In his final years of teaching and doing research, V.P. Skripov was concerned with the problems of metastable phase equilibria and thermodynamic similarity in liquid-crystal systems. The results obtained in this direction are presented in the book by V.P. Skripov and M.Z. Faizullin, Crystal-Liquid-Vapor Phase Transitions and Thermodynamic Similarity, which has been translated into English (Skripov and Faizullin, 2007). 
There are many outstanding scientists who have brought fame to science by their work. Organizers of science are also well known. But not every eminent scientist manages to create a group of researchers consisting of his own pupils who are united by a common scientific direction, i.e., to create a scientific school. V.P. Skripov succeeded in doing what other scientists did not manage to do. He could work with people of differing abilities, arouse their interest in investigating scientific problems, and show them respect. His communication style was straightforward and easy to understand, which not only promoted the professional advance of his pupils but also strengthened new initiatives in them. They saw that their teacher lived for the sake of science. He possessed the optimism of a creative, cheerful person.

In the period from 1965 to 2006 the school of V.P. Skripov prepared 16 doctors and more than 50 candidates of science. The results obtained by V.P. Skripov were highly appreciated by the scientific community. In 1981, he was awarded the Polzunov prize of the USSR Academy of Sciences, in 1987 was elected as a corresponding member to the USSR Academy of Sciences, and in 1992 became an academician to the Russian Academy of Sciences.

In 1999, for the series of papers "Metastable Liquids States: Fundamental Investigations and Applications to Energetics" (Skripov, 1974; Skripov and Koverda, 1984; Skripov et al., 1988; and Skripov and Faizullin, 2007), a group of research workers headed by V.P. Skripov was awarded the State Prize of the Russian Federation in the field of science and technology.

\section{Guest Editor:}

Vladimir G. Baidakov

Institute of Thermal Physics,

Ural Branch of Russian Academy of Sciences,

Ekaterinburg, 620016, Russia

\section{REFERENCES}

Skripov, V.P., Metastable Liquids, New York, NY: Wiley, 1974.

Skripov, V.P. and Koverda, V.P., Spontaneous Crystallization of Supercooled Liquids, Moscow, USSR: Nauka, 1984.

Skripov, V.P., Sinitsyn, E.N., Pavlov, P.A., Ermakov, G.V., Muratov, G.N., Bulanov, N.V., and Baidakov, V.G., Thermophysical Properties of Liquids in the Metastable (Superheated) State, New York, London, Paris, Montreux, Tokyo, Melburn: Gordon and Breach Science Publishers, 1988.

Skripov, V.P. and Faizullin, M.Z., Solid-Liquid-Gas Phase Transitions and Thermodynamic Similarity, Weinheim, Germany: WileyVCH Verlag GmbH, 2007.

Wakeshima, H. and Takata, K., On the Limit of Superheat, J. Phys. Soc. Japan, vol. 13, pp. 1398-1403, 1958. 